\title{
Evaluation of antioxidant potential of melatonin in periodontitis with a focus on vitamin $\mathrm{C}$
}

\author{
Anagha P. Marawar ${ }^{1 *}$, Pramod P. Marawar ${ }^{2}$, D. H. Nandal ${ }^{3}$, Rahul R. Kunkulol ${ }^{1}$
}

${ }^{1}$ Department of Pharmacology, ${ }^{2}$ Department of Periodontics, Rural Medical College, Loni, Ahmednagar, Maharashtra, India

${ }^{3}$ Department of Pharmacology, Birat Medical College, Biratnagar, Nepal

Received: 15 January 2020

Revised: 31 January 2020

Accepted: 01 February 2020

\section{*Correspondence:}

Dr. Anagha P. Marawar,

Email: annu777@gmail.com

Copyright: (c) the author(s), publisher and licensee Medip Academy. This is an open-access article distributed under the terms of the Creative Commons Attribution Non-Commercial License, which permits unrestricted non-commercial use, distribution, and reproduction in any medium, provided the original work is properly cited.

\begin{abstract}
Background: The present study was done with an objective to evaluate the effect of melatonin as an antioxidant, with a focus on vitamin $\mathrm{C}$, in patients suffering from periodontitis.

Methods: This study was conducted jointly in the Department of Periodontics, Rural Dental College, and Department of Pharmacology, PIMS, Loni. Patients suffering from chronic periodontitis, of age between 18 to 65 years of either gender were included in the study, after obtaining a written informed consent. Patients were divided into three Groups. Group A included patients who underwent scaling and root planning (SRP) alone, Group B included patients who underwent SRP and supplemented with vitamin E 200 IU daily at night for 4 weeks. Group C included patients who underwent SRP and supplemented with tablet melatonin $3 \mathrm{mg}$ daily at night for 4 weeks. Estimation of vitamin C was done on day 0 , day 30, day 60 and day 90.

Results: A total 240 patients were enrolled in the study, 80 in each group. Statistical analysis was done using ' $Z$ ' test of difference between two sample means for comparison of vitamin $\mathrm{C}$ among the three groups. It was observed that, there was a highly significant increase in mean values of vitamin $\mathrm{C}$ in group $\mathrm{C}$ when compared with group $\mathrm{A}$ and group B at 1st, 2nd and 3rd visits $(\mathrm{p}<0.01)$.

Conclusions: Melatonin acts as an antioxidant in the patients of periodontitis which has positive effect on biochemical parameters of periodontitis, conferring a new facet to the management of periodontitis and an attempt to impede the disease progression.
\end{abstract}

Keywords: Antioxidant, Melatonin, Periodontitis, Vitamin C

\section{INTRODUCTION}

Approximately $10-15 \%$ of population globally is affected by periodontal disease. ${ }^{1}$ In the Indian sub-continent, the numbers are as high as $75 \%$ for some form of gingival disease. Periodontitis is defined as "an infectious disease resulting in inflammation within the supporting tissue of the teeth, progressive attachment loss and bone loss" and is mediated by complex host parasite interactions, that leads to the loss of connective tissue attachment to root surface cementum and adjacent alveolar bone. ${ }^{2,3}$ In India, chronic periodontitis is observed to be the most common of all the forms of periodontal diseases with a high preponderance in adults. Majority of the pathological changes associated with periodontitis are irreversible, resulting in tooth loss and substantial morbidity, when focus of infection and subsequent bacteremia may present a significant risk. ${ }^{2}$ 
Periodontal disease is typically initiated by bacterial infection leading to inflammation, subsequently progresses via an aberrant host response, and primarily contributes to periodontal tissue destruction. ${ }^{4}$ Polymorphonuclear leukocytes (PMNs) are disparagingly involved in biophylaxis against periodontopathogens. ${ }^{5,6}$ They induce an antimicrobial response at the site of infection by triggering various intracellular signalling pathways, including reactive oxygen species (ROS). ${ }^{7}$ At higher concentrations, ROS exert a cytotoxic effect on periodontal tissues. ${ }^{8,9}$ Various studies have demonstrated that oxidative stress induced by PMNs can be the primary aetiology for the damage of periodontal tissue in periodontal disease. ${ }^{10}$ It is worth highlighting that patients with periodontitis have often revealed higher levels of biomarkers indicating ROS-induced-tissue damage than that observed in matched controls. ${ }^{11-13}$

Ascorbic acid or vitamin $\mathrm{C}$ is an important nutrient with proven antioxidant effect, with properties of scavenging free radicals, and acting as an enzyme cofactor in cells. Vitamin $\mathrm{C}$ can be considered as an important dietary oxidant for maintaining periodontal health, primarily due to its ROS scavenging action. It also plays a crucial role in decelerating the progression of periodontal disease the molecular mechanism of which is by inducing the differentiation of periodontal ligament progenitor cells. ${ }^{14}$

The mainstay of periodontal disease treatment has been dental procedures like scaling and root planning (SRP), prudent antimicrobial therapy and surgery as deemed appropriate depending on the patient profile. However, research has proven that SRP may be ineffective in up to $40 \%$ of patients, and when it does work, SRP reduces pocket depths by a little over $1 \mathrm{~mm}$ on an average. Another shortcoming of SRP is that, the nature of treatment is topical and has no impact whatsoever in decreasing the systemic pathogenesis of periodontitis. Surgery is often reserved as the ultimate therapy option; however, it comes with its own disadvantages of being expensive, painful and requires substantial expertise. Finally, antibiotics help tide over acute infections and inflammatory afflictions, nevertheless they are a temporary form of treatment and often futile in dealing with long term recurrences. In view of a therapy exerting systemic action, antioxidants may support the body's natural immune system, thus assisting to prevent the primary pathology and prevent long-term remissions.

The pineal gland produces a ubiquitous natural neurotransmitter like compound called melatonin. ${ }^{15}$ The role of endogenous melatonin in maintaining the human circadian rhythm and its role in sleep disorders is well studied and established. ${ }^{16}$ Apart from these effects, melatonin is also known to exert oncostatic effects, induce immune system stimulation and demonstrate antiinflammatory functions. Of late, melatonin has been recognized as a prevailing direct free radical scavenger and indirect antioxidant. ${ }^{17}$ Melatonin has been studied extensively and has shown to reduce oxidative stress attributable to several different mechanisms. On one hand melatonin acts as an active scavenger of both the highly toxic hydroxyl radical, and peroxy radical, which is generated during unsaturated lipid peroxidation. On the other hand, melatonin also stimulates some vital antioxidant enzymes, namely, superoxide dismutase, glutathione peroxidase, glutathione reductase and vitamin C. ${ }^{18}$ Of special interest in periodontal disease, it is proposed that melatonin may stimulate the proliferation and synthesis of type I collagen and bone formation. Apart from the systemic effects of melatonin, studies pertaining to salivary melatonin levels have shown to vary according to the degree of periodontal disease. This crucial information indicates that salivary melatonin may be effective in prevention of periodontal insults. In view of the research information available thus far, it is judicious to state that supplementation of melatonin (synthetic melatonin) may be possibly explored further and valued in the treatment of periodontal diseases. ${ }^{18}$

Evidences addressing nutritionally effective approaches must be generated for prevention and treatment of periodontal disease. Although there isn't much data available on melatonin and periodontal disease, several epidemiological studies have evaluated the association between vitamin $\mathrm{C}$ intake, effects of antioxidants and periodontal disease. In addition, the ability of vitamin $\mathrm{C}$ to prevent periodontal disease has been analysed in clinical studies too. Considering the above-mentioned functions of melatonin, this study was designed to evaluate the ability of melatonin supplementation to raise the antioxidant capacity levels and thereby reduce the periodontal inflammation. This study is also aimed to compare the efficacy of melatonin and vitamin $\mathrm{E}$ supplementation as antioxidants in periodontal diseases.

\section{METHODS}

The present study was a prospective, longitudinal type of study. The study commenced after the approval of Institutional ethical committee of Pravara Institute of Medical Sciences, Loni, Ahmednagar, Maharashtra, India. Patients satisfying the inclusion and exclusion criteria were included in the study after taking their written informed consent. Study was conducted at collaboration with the Department of Periodontics and Oral Implantology, Rural Dental College and Department of Biochemistry, Rural Medical College and Hospital, Loni. The study was carried out during the period of January 2008 to December 2008. The subjects enrolled for this study were selected from the Out-Patient Department of Periodontics, Rural Dental College, Loni, Maharashtra, India.

\section{Inclusion criteria}

Patients of chronic periodontitis, of age between 18 to 65 years of either gender ready to give informed consent to participate in the study were included. 


\section{Exclusion criteria}

Postoperative patients, patients having night duties, drivers and those using heavy machinery, pregnant women, lactating mothers, patients with any clinically significant systemic disease and patients on any other drugs were excluded from the study.

\section{Study groups}

Depending on the treatment received, there were three study groups.

Group A: Patients underwent SRP alone.

Group B: Patients underwent SRP and supplemented with vitamin E 200 IU daily at night for 4 weeks.

Group C: Patients underwent SRP and supplemented with tablet melatonin $3 \mathrm{mg}$ daily at night for 4 weeks.
The study participants visited on day 0 , day 30, day 60 and day 90. During the baseline visit scaling and root planning was performed in all patients. During these visits the estimation of vitamin $\mathrm{C}$ or ascorbic acid, depicting the antioxidant effect of melatonin was assayed by the method of Omaye et al. ${ }^{19}$ Statistical analysis was done by applying ' $Z$ ' test of difference between two sample means for comparison of vitamin $\mathrm{C}$ among the three groups.

\section{RESULTS}

In the present study, a total 240 patients were enrolled and evaluated in 2008. Table 1 shows the age and sex wise distribution of the subjects in all 3 groups under study. All the three groups consisted of 80 subjects each. Group A consisted of $71.25 \%$ male and $28.75 \%$ female patients. Male patients in group B were $58.75 \%$ and female $41.25 \%$. There were $56.25 \%$ male and $43.75 \%$ female patients in group $\mathrm{C}$.

Table 1: Age and sex wise distribution of the subjects under study.

\begin{tabular}{|c|c|c|c|c|c|c|}
\hline \multirow{2}{*}{ Age in years } & \multicolumn{2}{|l|}{ Group A } & \multicolumn{2}{|l|}{ Group B } & \multicolumn{2}{|l|}{ Group C } \\
\hline & $\mathbf{M}(\%)$ & F $(\%)$ & M (\%) & F $(\%)$ & M (\%) & F $(\%)$ \\
\hline$<40$ & $24(30)$ & $6(7.5)$ & $14(17.5)$ & $23(28.75)$ & $17(21.25)$ & $11(13.75)$ \\
\hline $40-50$ & $23(28.75)$ & $15(18.75)$ & $17(21.25)$ & $12(15)$ & $16(20)$ & $17(21.25)$ \\
\hline $50-60$ & $10(12.5)$ & $2(2.5)$ & $16(20)$ & $12(15)$ & $12(15)$ & $7(8.75)$ \\
\hline Total & $57(71.25)$ & $23(28.75)$ & $47(58.75)$ & $33(41.25)$ & $45(56.25)$ & $35(43.75)$ \\
\hline
\end{tabular}

M: male; F: female.

Table 2: Distribution of mean and SD values of antioxidant vitamin C at four visits in all groups under study.

\begin{tabular}{|llll|}
\hline $\begin{array}{l}\text { Antioxidant } \\
\text { vitamin C }\end{array}$ & Group A & Group B & Group C \\
\hline Base line visit & Mean \pm SD & Mean \pm SD & Mean \pm SD \\
\hline Visit 1 & $0.61 \pm 0.19$ & $0.67 \pm 0.07$ & $1.16 \pm 0.54$ \\
\hline Visit 2 $^{\text {nd }}$ & $0.66 \pm 0.05$ & $1.10 \pm 0.40$ & $1.24 \pm 0.44$ \\
\hline Visit 3 $^{\text {rd }}$ & $0.66 \pm 0.06$ & $1.42 \pm 0.41$ & $1.54 \pm 0.41$ \\
\hline
\end{tabular}

Table 3: Comparison of mean values of antioxidant vitamin $\mathrm{C}$ at four visits in group $\mathrm{A}$ and $\mathrm{B}$.

\begin{tabular}{|c|c|c|c|c|c|}
\hline Vitamin C & $\begin{array}{l}\text { Group A } \\
\text { Mean } \pm \text { SD }\end{array}$ & $\begin{array}{l}\text { Group B } \\
\text { Mean+SD }\end{array}$ & $\begin{array}{l}\text { ' } z \text { ' } \\
\text { value }\end{array}$ & P value & Result \\
\hline Base line visit & $0.61 \pm 0.19$ & $0.67 \pm 0.07$ & 2.65 & $<0.01$ & Highly significant \\
\hline Visit $1^{\text {st }}$ & $0.66 \pm 0.05$ & $1.10 \pm 0.40$ & 9.84 & $<0.01$ & Highly significant \\
\hline Visit $2^{\text {nd }}$ & $0.66 \pm 0.06$ & $1.42 \pm 0.41$ & 12.67 & $<0.01$ & Highly significant \\
\hline Visit $3^{\text {rd }}$ & $0.66 \pm 0.07$ & $1.15 \pm 0.38$ & 11.39 & $<0.01$ & Highly significant \\
\hline
\end{tabular}

Table 4: Comparison of mean values of antioxidant vitamin $\mathrm{C}$ at four visits in group $\mathrm{A}$ and $\mathrm{C}$.

\begin{tabular}{|c|c|c|c|c|c|}
\hline Vitamin C & $\begin{array}{l}\text { Group A } \\
\text { Mean } \pm \text { SD }\end{array}$ & $\begin{array}{l}\text { Group C } \\
\text { Mean } \pm \text { SD }\end{array}$ & $\begin{array}{l}\text { 'z' } \\
\text { value }\end{array}$ & $P$ value & Result \\
\hline Base line visit & $0.61 \pm 0.19$ & $1.16 \pm 0.54$ & 8.59 & $<0.01$ & Highly significant \\
\hline Visit $1^{\text {st }}$ & $0.66 \pm 0.05$ & $1.24 \pm 0.44$ & 11.84 & $<0.01$ & Highly significant \\
\hline Visit $2^{\text {nd }}$ & $0.66 \pm 0.06$ & $1.54 \pm 0.41$ & 19.13 & $<0.01$ & Highly significant \\
\hline Visit $3^{\text {rd }}$ & $0.66 \pm 0.07$ & $1.63 \pm 0.26$ & 32.33 & $<0.01$ & Highly significant \\
\hline
\end{tabular}


Table 5: Comparison of mean values of antioxidant vitamin $\mathbf{C}$ at four visits in group $\mathbf{B}$ and $\mathbf{C}$.

\begin{tabular}{|c|c|c|c|c|c|}
\hline Vitamin C & $\begin{array}{l}\text { Group B } \\
\text { Mean } \pm \text { SD }\end{array}$ & $\begin{array}{l}\text { Group C } \\
\text { Mean } \pm \text { SD }\end{array}$ & $\begin{array}{l}\text { ' } z ' \\
\text { value }\end{array}$ & P value & Result \\
\hline Base line visit & $0.67 \pm 0.07$ & $1.16 \pm 0.54$ & 8.16 & $<0.01$ & Highly significant \\
\hline Visit $1^{\text {st }}$ & $1.10 \pm 0.40$ & $1.24 \pm 0.44$ & 2.12 & $<0.01$ & Highly significant \\
\hline Visit $2^{\text {nd }}$ & $1.42 \pm 0.41$ & $1.54 \pm 0.41$ & 3.12 & $<0.01$ & Highly significant \\
\hline Visit $3^{\text {rd }}$ & $1.15 \pm 0.38$ & $1.63 \pm 0.26$ & 9.60 & $<0.01$ & Highly significant \\
\hline
\end{tabular}

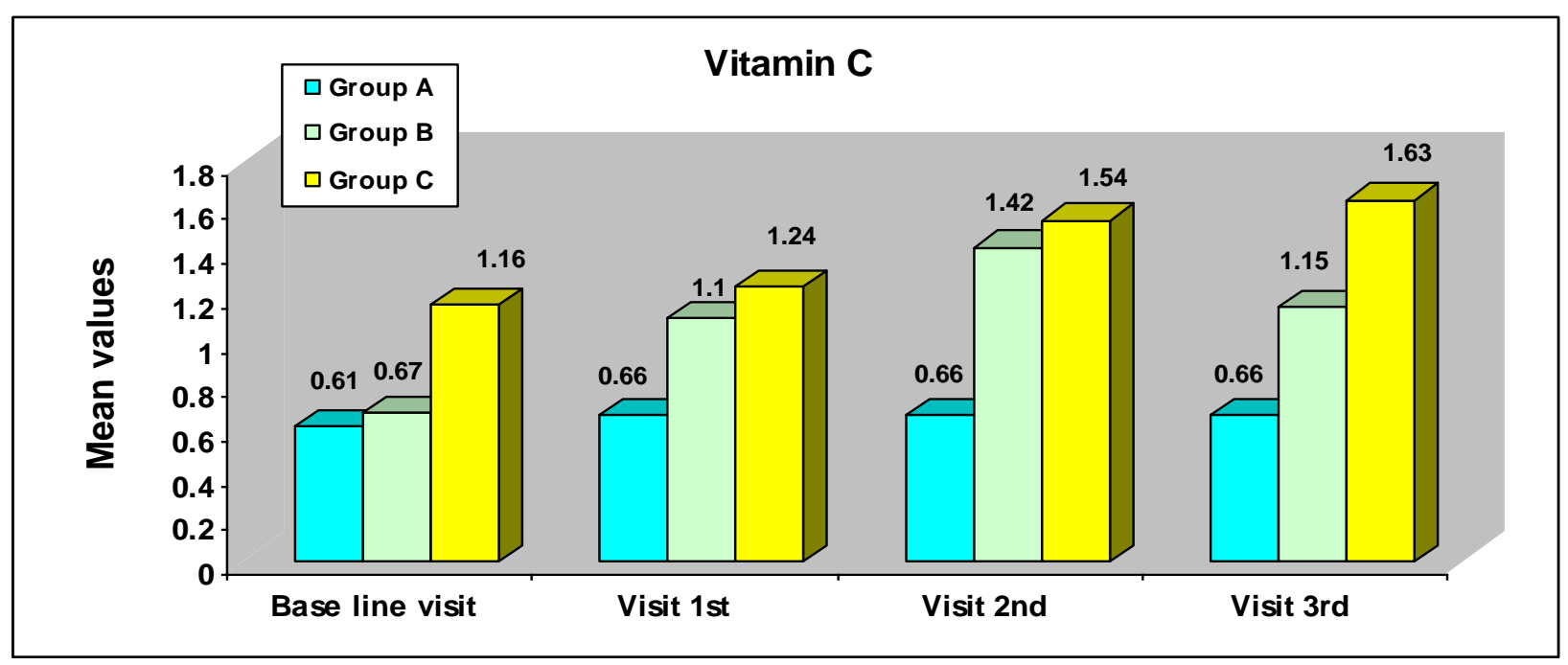

Figure 1: Comparison of mean values of vitamin $\mathrm{C}$ at four visits amongst all the groups.

Distribution and comparison of values of vitamin $\mathrm{C}$ in all groups at all visits are shown in Table 2 and Figure 1 respectively.

Table 3, 4 and 5, depict the comparison of mean values of antioxidant vitamin $\mathrm{C}$ at four visits in group $\mathrm{A}$ and $\mathrm{B}$, in group $\mathrm{A}$ and $\mathrm{C}$ and in group $\mathrm{B}$ and $\mathrm{C}$, respectively.

It was observed that, by applying ' $Z$ ' test of difference between two sample means, there was a highly significant increase in mean values of vitamin $C$ in group $C$ when compared with group $\mathrm{A}$ at 1st, 2nd and 3rd visits $(\mathrm{p}<0.01)$. There was a highly significant increase in mean values of vitamin $\mathrm{C}$ in group $\mathrm{C}$ when compared with group $B$ at all visits $(\mathrm{p}<0.01)$.

\section{DISCUSSION}

The aim of this study was to evaluate the antioxidant effect of administration of oral melatonin in periodontitis patients in rural population, with a focus on vitamin $\mathrm{C}$.

Chronic periodontitis is characterized by inflammatory destruction of connective tissue, loss of periodontal attachment and resorption of alveolar bone. Free radicals (FR) generation during inflammatory process may be relevant in the development of these alterations. There is increasing evidence that the disease occurs in a predisposed group of the population that has an aberrant inflammatory or immune response to the microbial plaque that accumulates around the gingival margin. This exaggerated response is known to result in inadvertent or collateral host tissue damage. ${ }^{2}$

The predominant inflammatory cell within the healthy connective tissues and epithelium of the gingiva is the polymorphonuclear leucocytes (PMNL). In aggressive and chronic forms of periodontitis, PMNLs appear to be functionally activated and exhibit increased production of ROS. These molecules are reported to be capable of inducing periodontal tissue destruction and are associated with osteoclastic bone resorption. The degree to which ROS influence the progression of periodontal diseases is yet unclear, but their role cannot be considered in isolation, given the range of antioxidant species that protects against excess ROS activity and maintains a delicate equilibrium within host tissues.

Battino et al in their review on oxidative injury and periodontal diseases concluded that, FR or ROS are essential to many normal biological processes, and low doses of certain radicals or radical-derived species can stimulate the growth of fibroblasts and epithelial cells in culture. ${ }^{20}$ When antioxidant systems are unable to counteract their action efficiently, tissue damage can result. A low FR or ROS often behaves as an inductor stimulus, whereas higher levels may result in injury. 
The ability of the host to scavenge ROS produced by leucocytes or other cells (for example, fibroblasts) is regarded as a key protective mechanism against inadvertent ROS mediated host tissue damage. This mechanism appears to be crucial in both acute and chronic inflammatory diseases. ${ }^{21}$

Several studies have revealed an association between reduced dietary vitamin $\mathrm{C}$ and an increased risk for periodontal disease. ${ }^{22}$ Chapple et al demonstrated that the prevalence of severe periodontitis was significantly higher in the subjects with serum vitamin C levels $<8.52 \mathrm{mmol} / 1$, compared with subjects with other vitamin C concentrations. $^{23}$ The serum vitamin $\mathrm{C}$ levels were compared between the patients with periodontal disease and the controls in two case-control studies. ${ }^{24,25}$ Both studies demonstrated that periodontitis patients have significantly lower serum vitamin $\mathrm{C}$ levels compared with the controls. Populations with a higher dietary intake or higher serum levels of vitamin $\mathrm{C}$ exhibited slower periodontal disease progression.

Melatonin, the major secretory product of the pineal gland, is involved in the regulation of circadian rhythms and seasonal changes in vertebrate physiology via the daily nocturnal increase and release from the pineal. Because melatonin production is highest at night, this mediator has been described as the chemical expression of darkness. In addition; melatonin shows a remarkable functional versatility exhibiting antioxidant, oncostatic, antiaging and immunomodulatory properties.

The findings in our study indicate the important role played by melatonin in combating the oxidative stress by increasing the levels of vitamin $\mathrm{C}$ in periodontitis at well tolerated doses. In view of this antioxidant action, a combination of antioxidant vitamins may also be considered in the treatment of periodontitis.

Since the discovery of melatonin as an antioxidant in 1993 (Tan et al), there has been a burgeoning number of reports documenting this action under an almost unlimited number of conditions, many of which have direct clinical relevance. Thus, melatonin has been shown to reduce the toxicity of drugs and in some cases improve their efficacy, to reduce the severity and degree of tissue damage following ischemia/reperfusion in the brain and other organs, to prevent degenerative changes in the CNS in models of Alzheimer's and Parkinson's disease, to reduce free radical damage to DNA which may lead to cancer, and many other situations too numerous to mention in this brief report. Considering these facts, this study was conducted to throw light on the effects of melatonin on patients suffering from periodontitis in rural scenario.

Vitamin $\mathrm{C}$ is one of the important antioxidants necessary for removal of many of the free radicals. In our study, there was a highly significant increase in the mean values of vitamin $\mathrm{C}$ in group $\mathrm{B}$ and $\mathrm{C}$ when compared with group $\mathrm{A}$ at all visits $(\mathrm{p}<0.01)$. Nevertheless, the treatment duration in our study was one month and since periodontitis can recur, it would be worthwhile to conduct a study with prolonged treatment with melatonin, involving a larger sample size.

\section{CONCLUSION}

It was observed that the considerable oxidative stress in periodontitis patients, was significantly reduced by melatonin by virtue of increase in vitamin $\mathrm{C}$, reflecting its antioxidant potential. With the above background, it can be said that melatonin acted as an antioxidant in the patients of periodontitis which has positive effect on biochemical parameters of periodontitis, conferring a new facet to the management of periodontitis and an attempt to impede the disease progression.

Thus, this study amply justifies the role of melatonin in the control of periodontal disease and the conclusions drawn could be useful in generating further studies. It is felt that information gained from this study would evolve measures by which the same can be applied for the preventive periodontal campaign and thereby help in reducing menace of periodontal diseases, the incidence and prevalence of which has been found to be very high in India and other developing countries.

Furthermore, vitamin $\mathrm{C}$ administration has been observed to improve periodontal disease to some extent in certain intervention studies. It could be worthwhile to explore the role of vitamin $\mathrm{C}$, both in prophylaxis and treatment, with regard to periodontal disease.

In conclusion, our study has demonstrated a significant antioxidant effect of melatonin in patients suffering from periodontal disease. It is worth mentioning that, vitamin $\mathrm{C}$ supplementation may have a major prophylactic role in the said disease. Thus, in addition to the standard of care i.e. SRP and vitamin E supplementation, melatonin can be considered as a novel addition in the armamentarium of treatment for periodontal disease.

\section{Funding: No funding sources}

Conflict of interest: None declared

Ethical approval: The study was approved by the Institutional Ethics Committee of Pravara Institute of Medical Sciences, Ahmednagar, Maharashtra, India

\section{REFERENCES}

1. Free radical scavenging is defective in tooth disease, Available at: https://www.nutraingredients.com/ Article/2002/11/26/Free-radical-scavenging-isdefective-in-tooth-disease Accessed on 07 February 2020.

2. Chapple ILC. Role of free radicals \& antioxidants in the pathogenesis of the inflammatory periodontal diseases. J Clin Pathol 1996;49:247-55. 
3. Chronic periodontitis, In: Newman, Takei, Klokkevold, Carranza, eds. Carranza's Clinical Periodontology. 10th ed. New Delhi: Elsevier Publications; 2007: 494-499.

4. Bartold PM, Van Dyke TE. Periodontitis: A host mediated disruption of microbial homeostasis. Unlearning learned concepts. Periodontology. 2013;62:203-17.

5. Miller DR, Lamster IB, Chasens AI. Role of the polymorphonuclear leukocyte in periodontal health and disease. J Clin Periodontol. 1984;11:1-15.

6. Van Dyke TE, Levine MJ, Genco RJ. Neutrophil function and oral disease. J Oral Pathol. 1985;14:95120.

7. Nguyen GT, Green ER, Mecsas J. Neutrophilsto the ROScue: Mechanisms of NADPH Oxidase Activation and Bacterial Resistance. Front Cell Infect Microbiol. 2017;7:373.

8. Galli C, Passeri G, Macaluso GM. FoxOs, Wnts and oxidative stress-induced bone loss: New players in the periodontitis arena? J Periodontal Res. 2011;46:397-406.

9. Saita M, KanekoJ, Sato T, Takahashi SS, WadaTakahashi S, Kawamata R, et al. Novel antioxidative nanotherapeutics in a rat periodontitis model: Reactive oxygen species scavenging by redox injectable gel suppresses alveolar bone resorption. Biomaterials. 2016;76:292-301.

10. Wang Y, Andrukhov O, Rausch-Fan X. Oxidative Stress and Antioxidant System in Periodontitis. Front Physiol. 2017;8:910.

11. Sculley DV, Langley-Evans SC. Periodontal disease is associated with lower antioxidant capacity in whole saliva and evidence of increased protein oxidation. Clin Sci. 2003;105:167-72.

12. Panjamurthy K, Manoharan S, Ramachandran CR. Lipid peroxidation and antioxidant status in patients with periodontitis. Cell Mol Biol Lett. 2005;10:25564.

13. Sugano N, Kawamoto K, Numazaki H, Murai S, Ito $\mathrm{K}$. Detection of mitochondrial DNA mutations in human gingival tissues. J Oral Sci. 2000;42:221-3.

14. Tada A, Miura H. The Relationship between Vitamin C and Periodontal Diseases: A Systematic Review. Int J Environ Res Public Health. 2019;16:2472.

15. Malhotra S, Sawhney G, Pandhi P. The therapeutic potential of melatonin: a review of the science. MedGenMed. 2004;6(2):46.
16. Kantarci A, Thomas E, Van Dyke. Resolution of inflammation in Periodontitis. $\mathrm{J}$ Periodontal. 2005;76(11):2168-74.

17. Russel RJ, Dun-Xian, Juan C, Mayo. Melatonin as an antioxidant: Biochemical mechanisms and pathophysological implications in humans. Acta Biochemica Polonica. 2003;50(4):1129-46.

18. Russel RJ, Corneiro RC, Oh CS. Melatonin in relation to cellular antioxidative defence mechanisms. Horm Metab Res. 1997;29(8):263-72.

19. Omaye ST, Turnbull JD and Saurberlich H. Selected methods for the determination of ascorbic acid in animal cells, tissues and fluids. Meth Enzymol. 1971;62:3-11.

20. Battino $M$, Bullon $P$, Wilson $M$, Newman $H$. Oxidative injury and inflammatory periodontal diseases. The challenge of antioxidants to free radicals and reactive oxygen species. Crit Rev Oral Biol Med. 1999;10(4):458-76.

21. Cutando A, Galindo P, Gomez-Moreno G. Relationship between salivary melatonin and severity of periodontal disease. J Periodontal. 2006;77:15338.

22. Nishida M, Grossi SG, Dunford RG, Ho AW, Trevisan M, Genco RJ. Dietary vitamin C and the risk for periodontal disease. J Periodontol. 2000;71:1215-23.

23. Chapple IL, Milward MR, Dietrich T. The prevalence of inflammatory periodontitis is negatively associated with serum antioxidant concentrations. J Nutr. 2007;137:657-64.

24. Kuzmanova D, Jansen ID, Schoenmaker T, Nazmi K, Teeuw WJ, Bizzarro S, et al. Vitamin $\mathrm{C}$ in plasma and leucocytes in relation to periodontitis. J Clin Periodontol. 2012;39(10):905-12.

25. Staudte H, Kranz S, Völpel A, Schütze J, Sigusch BW. Comparison of nutrient intake between patients with periodontitis and healthy subjects. Quintessence Int. 2012;43:907-16.

Cite this article as: Marawar AP, Marawar PP, Nandal DH, Kunkulol RR. Evaluation of antioxidant potential of melatonin in periodontitis with a focus on vitamin C. Int J Basic Clin Pharmacol 2020;9:378-83. 